\title{
LO MONSTRUOSO DESDE EL HUMOR EN EL POEMARIO ÉRASE ESTE MONSTRUO DE FLORIA JIMÉNEZ
}

Magdalena Vásquez Vargas

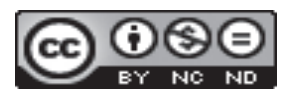

Esta obra está bajo una licencia Creative Commons

Reconocimiento-No Comercial-Sin Obra Derivada 



\title{
LO MONSTRUOSO DESDE EL HUMOR EN EL POEMARIO ÉRASE ESTE MONSTRUO DE FLORIA JIMÉNEZ
}

\author{
THE MONSTROUS FROM THE HUMOROUS IN THE POETRY BOOK \\ ÉRASE ESTE MONSTRUO BY FLORIA JIMÉNEZ
}

\author{
Magdalena Vásquez Vargas
}

\begin{abstract}
RESUMEN
En esta ponencia se analiza el texto Érase este monstruo de la escritora costarricense Floria Jiménez Díaz. Este libro obtuvo el Premio Carmen Lyra en el 2003. El objetivo principal es determinar cómo esta autora logra invertir el efecto de terror que lo monstruoso ha provocado en los lectores infantiles, ya que en sus poemas, los monstruos adquieren una nueva caracterización que los lleva a provocar risa en vez de miedo. Se estudian de forma específica los recursos retóricos que contribuyen a la producción del humor, así como el modo en que se resignifican los monstruos, cuyo origen se encuentra en el folclor universal y en el costarricense. También se analiza en qué medida este texto se relaciona con la concepción que Floria Jiménez tiene sobre la literatura y poesía infantil, expuesta en su libro Literatura para niños (2001). Lo anterior con el propósito de explicar la función que para ella cumple este tipo de literatura, definir su proyecto estético y precisar su aporte a la literatura infantil costarricense.

Palabras clave: literatura infantil, lo monstruoso, humor, Jiménez Díaz-Floria, Érase este monstruo.
\end{abstract}

\begin{abstract}
This paper analyzes the text Érase este monstruo by Costa Rican writer Floria Jimenez Diaz. This book won the Carmen Lyra Award in 2003. The main objective is to determine how the author manages to reverse the terror that monsters cause in young readers, since in his poems, the monsters acquire new characteristics that aims to provoke laughter rather than fear. We shall study rhetorical devices that contribute to the production of humor, and the way the monsters are re-signified. It also analyzes how this text relates to Floria Jimenez's ideas on children's literature and nursery rhymes, presented in her book Literature for Children (2001). This with the purpose of explaining the role of this brand of literature, define her aesthetic project and determine her contribution to Costa Rican children's literature.
\end{abstract}

Key words: Children's Literature, the Montrous, Humor, Floria Jiménez Diaz, Érase este monstruo.

Dra. Magdalena Vásquez Vargas. Universidad de Costa Rica. Sede de Occidente. Profesora catedrática del Departamento de Filosofía, Artes y Letras. Costa Rica.

Correo electrónico: magdalena.vasquez.ucr@gmail.com

Recepción: 23- 02- 2015

Aceptación: 19- 06- 2015 
El lector infantil está implicado, como todo lector, en el proceso de creación del universo semántico literario, pero, la relación que establece el libro para niños con su público, es esencialmente compleja. (Origgi, 2004, p. 9)

\section{El concepto de poesía y su relación con el receptor infantil}

En el desarrollo de la literatura costarricense, hay dos autoras que, además de dedicarse a cultivar la literatura para niños, han reflexionado sobre la literatura infantil como práctica literaria, tanto desde su especificidad como en relación con el tipo de lector a quien se dirige: Adela Ferreto Segura en Las fuentes de la literatura infantil y el mundo mágico (1984) y Floria Jiménez Díaz en Literatura para niños (2001). En este segundo libro la autora, a partir de conceptos teóricos como poesía infantil y sensibilidad creadora, delimita las funciones y características de la literatura infantil y elabora un texto didáctico que permite al docente contar con material de apoyo para llevar al aula escolar los distintos géneros de la literatura infantil. Asimismo, utiliza para cada una de las definiciones, como poesía humorística, narrativa y dialogada, ejemplos producto de su creación propia. Floria Jiménez ha cultivado, además, la narrativa y la poesía infantil y ha obtenido en tres oportunidades el Premio Carmen Lyra: en 1977 con Mirrusquita, en 2004 con Érase ese monstruo y en 2008 con La tía Poli y el gato fantasma. También en 1978 obtuvo el Premio Aquileo Echeverría con Me lo contó un pajarito.

Floria Jiménez expresa que el origen del lenguaje literario se encuentra en la oralidad, ya que el hablante en su expresión cotidiana emplea imágenes literarias, con lo que transforma intencionalmente el lenguaje, acentúa ciertos énfasis en su mensaje y logra captar la atención de su interlocutor. Al desarrollar el tema de la poesía para niños, subraya la relación que tiene el receptor infantil con el lenguaje literario y además, destaca la importancia de cultivar la apreciación de la poesía en los niños para lograr el hábito de la lectura. En lo referente al receptor infantil, afirma que la cercanía que ha tenido desde muy pequeño el infante con la musicalidad del lenguaje y los juegos de palabras, por medio de las canciones de cuna, los trabalenguas, las adivinanzas y otras manifestaciones estéticas, se constituye en una de las razones principales que permite acercar de manera natural la poesía a los niños, como parte de un proceso de goce con la palabra. Insiste también que la poesía agrada a los niños por su atracción auditiva y por las cualidades sonoras, las cuales generalmente trascienden el entendimiento. Para ella:

\footnotetext{
Los primeros pasos de la poesía nacen en el arrullo de cuna y en el enredijo de palabras de los niños en sus juegos. Los niños conversan con sus muñecos, con sus amigos imaginarios, con sus animales, con el sol, con toda la naturaleza. Reviven, por obra de su fantasía, a todos los elementos que motiven su interés, porque los niños son poetas por naturaleza y saben a su manera transcender la realidad (Jiménez-Díaz, 1994, p. 197)
}

De acuerdo con lo expuesto por Floria Jiménez, la fascinación que siente el niño por la poesía no está centrada en los significados de las palabras, sino en su musicalidad, en el ritmo, las melodías y el juego con los sonidos. El gusto por la poesía contribuirá a que progresivamente tome consciencia de los elementos sonoros y de la relación de estos con el significado: "La poesía para niños establece la comunicación entre el escritor y el pequeño espectador. El poeta logra transmitir su experiencia, intuición o sentimiento, por medio del 
juego de sonidos e imágenes, con lo que se producen variados efectos visuales, sonoros o musicales, simplemente." (Jiménez-Díaz, 2004, p. 198).

Existe una relación directa entre la forma en que Floria Jiménez conceptualiza la poesía infantil y su producción poética, la cual se caracteriza fundamentalmente por su sonoridad, lograda con diferentes recursos como la rima, ritmo, aliteraciones, anáforas, reiteraciones, entre otros. Sus poemas, propician, por lo tanto, que el infante entre al juego poético por medio de los sonidos y se quede en él al encontrarse con figuras literarias que son de su agrado como hipérboles, personificaciones, símiles, las cuales lo introducen en un mundo animado y mágico. De esta manera su poesía cumple con el rasgo fundamental de la poesía para niños, el que según Cervera (1991, p. 81), es propiciarle al niño la oportunidad de manejar las palabras, de contemplarlas desde distintos ángulos y jugar con ellas, siendo lo más importante el valor lúdico ante el informativo.

Ahora bien, después de lo expuesto, se tiene claro que Floria Jiménez, nos provoca con varios retos al analizar su libro Érase este monstruo, los cuales están orientados hacia su forma de abordar y representar el tema de lo monstruoso: ¿En qué medida existe una correspondencia entre su faceta como teórica y escritora de literatura infantil?, ¿qué relación se presenta entre el empleo de los rasgos que ella considera debe poseer la literatura infantil y la desmitificación de los monstruos que ella efectúa en su obra? A estas interrogantes también se le adiciona una más, en la que participa su labor cómo formadora de educadores y promotora de lectura: ¿Cuál es la intencionalidad de usar el humor como recurso neutralizador del efecto que produce lo monstruoso en el lector infantil?

\section{Desmitificación de los monstruos e inversión del efecto de lo monstruoso}

La Real Academia Española de la Lengua Española define el término "monstruo" como producción contra el orden de la naturaleza, ser fantástico que causa espanto, cosa excesivamente grande o extraordinaria en cualquier línea, persona o cosa muy fea, persona muy cruel y perversa (Real Academia Española, 1997, p. 1396). De esta definición es importante destacar, por un lado, la imprecisión del sustantivo que se califica, el cual se denomina: producción, ser, cosa, persona o cosa, y por el otro, los calificativos o atribuciones que se le dan: que causa espanto, excesivamente grande, muy feo, cruel y perverso. Esta conceptualización permite construir un campo semántico para la caracterización de lo monstruoso que responde a rasgos negativos que se incrementan cuando se describe al monstruo, como un ser (cosa) de excesiva grandeza.

Por su parte, Rafael Ángel Herra (1987) en su ensayo Lo monstruoso y lo bello, realiza una amplia investigación sobre la presencia y el significado de lo monstruoso en diferentes manifestaciones del ser humano y del arte. Para él lo monstruoso aparece articulado a la condición humana y por ello debe interpretarse desde una perspectiva muy amplia en la que existen relaciones dialécticas en las que el campo semántico de la maldad es uno de los principales generadores de sentido. Herra se pregunta:

\footnotetext{
¿Qué es, pues, el monstruo? ¿Qué otros problemas plantea interrogarse por los monstruos imaginarios? ¿Subsisten aún las bestias sagradas, como en los bestiarios antiguos y medievales? ¿Existen necesidades morales, es decir, obligantes y difusas, de lo monstruoso? ¿Se trata de una condición simbólica, fetichista, de buena conciencia, para sobrevivir? ¿Lo monstruoso forma parte de esas oscuras tendencias (¿sociales, psíquicas, biológicas?) que impulsan la contraposición del bien y el mal, fealdad y belleza; o que interesadamente llevan a su integración en totalidades concretas como las obras de arte? (HerraRodríguez, 1987, p. 21)
} 
En esta ponencia interesa, a partir de la definición de la Real Academia Española y de lo aportado por el crítico Herra, conocer la forma en que Floria Jiménez manipula lo monstruoso para lograr en su poemario invertir el campo semántico al que refiere el concepto y producir un efecto contrario en los niños ante la monstruosidad.

Desde su título (Érase este monstruo) el poemario sugiere que lo monstruoso tiene que ver con el pasado, principalmente por medio de la forma verbal "érase". Esta referencia al pasado permite asumir lo monstruoso como inofensivo, lo cual se enfatiza en el poema que da inicio al texto, con la utilización de la hipérbole para caracterizar al personaje: "Érase este monstruo tan grande, tan grande, que se dio un trancazo en el sol de la tarde". Además, el monstruo presentado es un ser híbrido: rabito de iguana, patas de estambre, barbas de chivo, nariz de camello (Jiménez-Díaz, 2008, pp. 9 y 11). A estos rasgos, que de por sí aportan comicidad al poema, se le unen otras imágenes que permiten aún más la desmitificación del monstruo, entendida como el proceso de transformación y humanización al que es sometido: "Érase este monstruo nariz de camello con diez chilindrines colgando del cuello." (Jiménez-Díaz, 2008, p. 11). La palabra chilindrines es entendida por Quesada-Pacheco (1991, p. 71) en el Diccionario de costarriqueñismos como aparatos sonajeros o cascabeles, hecho que convierte al monstruo en un ser que propicia la risa y no la temeridad con que tradicionalmente se le ha asociado.

El humorismo que provoca el personaje se acentúa cuando se introduce su participación directa en el poema: “¡Socorro, el zancudo! ¡Me pica la hormiga! ¡La alergia! Este gato! La lluvia, iqué fría!” (Jiménez-Díaz, 2008, p. 11). También es importante considerar que el empleo del contraste en la descripción del personaje es motivo de risa ya que al principio el monstruo es tan grande que se da un trancazo en el sol de la tarde y al final "Vive en la gaveta de un escaparate como servilleta doblado en tres partes" (Jiménez-Díaz, 2008, p. 11). De este modo y mediante la caracterización del monstruo se crea la imagen de él como un ser miedoso y risible. La misma frase del poema "Érase ese monstruo qué calamidad", representa un cambio total en el concepto genérico de monstruo, que tiene fuerza, fealdad y aterroriza.

A pesar de que los monstruos creados por esta autora no corresponden al concepto dado por la Real Academia Española, sí existe una clara asociación con la forma como Raúl Dorra (1994, p. 15) concibe a los monstruos, ya que para él son producto de una norma que resulta violada, de una deformación o un desvío del orden natural o del orden divino, una desmesura o una carencia que violenta la armonía de los seres. El monstruo analizado presenta un desorden físico y también moral, lo que se constata en la cobardía para enfrentar los peligros, puesto que se vuelve temeroso de seres mínimos como el zancudo y la hormiga.

Este libro muestra un inventario de monstruos: el Coco, los vampiros, las brujas, los ogros, los fantasmas y la Tulevieja. Todos ellos resultan modificados y transformados, de tal forma que ya no pueden ubicarse de manera maniquea como representantes de las fuerzas negativas. En los poemas los monstruos se muestran como seres débiles, necesitados de consejo y compañía. Ejemplo de lo anterior es el Coco, a quien la autora dedica el poema "Pobrecito el Coco". Este monstruo que tiene como referente las canciones de cuna traídas de España y Portugal, y que era quien se encargaba de asustar a los niños que no se querían dormir, es alterado en la poesía de tal manera que mueve a la conmiseración más que al miedo. Difícilmente un niño va a temer a un Coco que no tiene ni casa, ni oficio, ni gorra y menos costal. Además, la anáfora "Pobrecito el Coco", repetida en tres ocasiones en el poema, sirve para que el lector infantil asuma una actitud de compasión hacia este ser: 
Pobrecito el Coco./ De tanto buscar,/ ya no encuentra un chico/ a quien asustar./ Cuando venga el Coco,/ voy a revisar/ su bolso raído/ de tanto esperar./ Dicen que ha guardado/ por la eternidad /piedras y botellas/ dentro del costal./ Y todos pensaban: -El Coco, jahí va!/ Escóndete, chico,/ que te va a llevar./ Pobrecito el Coco/ ¿De qué vivirá,/ sin casa ni oficio/ gorra ni costal? (Jiménez-Díaz, 2008, pp. 15-17)

Es pertinente destacar también que la competencia literaria que tienen los niños, la cual se ha formado como producto de las múltiples historias escritas u orales que han escuchado, les permite identificar a los personajes: brujas, ogros y vampiros, con seres negativos. La lectura del poemario produce el extrañamiento en el lector infantil al presentar los seres monstruosos, despojados de su maldad y convertidos en seres inofensivos. La desmitificación aunada a los recursos como los juegos de palabras, las exageraciones y la musicalidad, es causante de una reacción distinta en el lector: el tránsito del horror a la risa. Véase el siguiente ejemplo en que se alude a diferentes animales monstruosos:

\begin{abstract}
Grandes y chiquitos,/ vengan a admirar/ la Casa de los Sustos/ de Curubandá./ (Dice un gran letrero/ de publicidad)/ De primera entrada,/ verás al caimán/ con sus diez cabezas/ y un ojo de más./ Por un laberinto/ te van a llevar./ Gritos y lamentos/ podrás escuchar./ Muchas calaveras/ te saludarán/ vuelta de cabeza,/ te divertirán./ La araña peluda/ de verde fustán/ colgada en el techo,/ maromas te hará./ Catorce murciélagos/ con traje espacial/ dentro de una esfera/ todos rodarán. (Jiménez-Díaz, 2008, pp. 81-83)
\end{abstract}

Otro de los personajes que se presenta es la Tulevieja, monstruo caracterizado en el folclor popular como un ser errante que asusta a niños y hombres. Sobre él hay muchas interpretaciones, por ejemplo, en la que se describe como una mujer con un sombrero de tule deformado y sucio que perseguía a los niños si la molestaban, hasta la que la califica como un ser híbrido, con alas. Se construye, por lo tanto, a partir de la semejanza y diferencia con los referentes conocidos y se enfatiza en la discrepancia, la que la acerca a lo monstruoso. La autora, la presenta en el poemario de la siguiente manera: “¡Aquí va Tulevieja./ buscando la casa/ de la comadreja!/ Los ojos tan rojos,/ tan largas las greñas,/ tan sucias las uñas,/ tan flacas las piernas" (Jiménez-Díaz, 2008, p. 21). La desmitificación se logra cuando es aconsejada a que cambie de actitud y presentación personal, con el fin de que logre la felicidad: "Ponete unas flores,/ sembrate una huerta,/ buscate un amigo/ que mucho te quiera./ Reíte, reíte/ y adiós la tristeza" (Jiménez-Díaz, 2008, p. 23). En fin, la asociación que se hace de la Tulevieja con lo tenebroso se transforma al presentarse como una mujer solitaria, abandonada, que mueve a la misericordia y a la compasión.

\title{
3. Empleo de una retórica de transformación del terror en humor
}

La desmitificación de lo monstruoso no solo es producto de la caracterización distinta de los monstruos en los poemas de esta autora que genera conmiseración y risa ante ellos, ya que se logra básicamente por el empleo de una serie de recursos lúdicos que son los responsables de esta variación del efecto de lo monstruoso que conduce al humor.

Para Zavala (1993, pp. 14-15), el humor se produce en un determinado contexto cultural y se constituye en un disparador semántico que se sustenta en el principio de la contradicción, y más específicamente en formas de incongruencia y hostilidad con respecto a aquellos modelos o estereotipos culturales que el escritor pretende deconstruir y representar. De igual manera afirma este crítico que el humor es un mecanismo de relajación, mediante el cual es posible transgredir normas y comportamientos sociales.

El humor es considerado también como un recurso que produce un impacto positivo en el niño y que según Maité Dautant (2009, p. 3), lo ayuda a que sobrelleve el mundo adulto 
con sus normas y controles interminables, y emprenda el camino del crecimiento con menos ansiedad, en el que definitivamente tiene contacto con múltiples significados y visiones del mundo más flexibles que las de los adultos. Precisamente Cervera (1991, p. 205) ha llamado "efecto tropezón" a la reacción que toma el niño cuando se ve obligado a interpretar y a darle un nuevo sentido a determinados códigos, generando una desviación de las normas.

De acuerdo con lo anterior, en Érase un monstruo el humor se construye mediante juegos semánticos sustentados en recursos como la hipérbole, el contraste, la sonoridad y la adjetivación. Ahora bien, según el teórico de la literatura infantil Juan Cervera:

\begin{abstract}
La situación humorística puede producirse también por medio del lenguaje tanto por el choque de los sonidos, como por la expresión de frases con contenido sorprendente, que traducen verbalmente una situación. Por ejemplo, si un personaje se llama Cuchifritín, su nombre suscita una sonrisa; y si se dice que un elefante enano es pequeño como un guisante, también. (1991, p. 76)
\end{abstract}

En el caso del poema "Esa ogresa patitiesa", el adjetivo con el que se califica al monstruo contribuye a que el receptor asuma una actitud distinta ante el personaje, ya que la palabra "patitiesa", la presenta como desvalida, lo que le quita el efecto de temeridad, como se aprecia en la siguiente cita:

Esa ogresa patitiesa/ quiere aprender a nadar,/ pero un pez le ha contestado:/ ¿No me vas a destripar?/
Esa ogresa patitiesa/ quiere aprender a saltar,/ pero una pulga le dice:/ -No me vayas a majar./ Esa ogresa
patitiesa/quiere aprender a correr,/ pero una liebre le dice:/ -No me vayas a vencer/ Y esa ogresa patitiesa/
quiere aprender a reír./ El pez, la pulga y la liebre/ la invitan a un gran festín. (Jiménez-Díaz, 2008, p. 67)

En este poema mediante la anáfora se enfatizan las calidades de invalidez del personaje presentado, ya que las preguntas retóricas efectuadas por el pez, la pulga y la liebre, que le piden a la ogresa que no los destripe o venza, producen un efecto humorístico por el contraste: las características de la ogresa, como gigante, insociable y de mal carácter, se contraponen a lo pequeño de la pulga.

La hipérbole se constituye también en otro de los recursos que generan comicidad en el texto, ya que la exageración desmedida lleva al lector niño a divertirse: “¿Qué comen los monstruos?/ Los monstruos se comen/ muchas golosinas, /dicen los tratados/ de buena cocina,/ que se han engordado/cuatrocientos kilos/ de tanta cuchara/con tanto comino./ Por rejas y hendijas/ no pueden pasar,/ subir los tejados/ los puede agitar./ ¿Qué comen los monstruos/ que gordos están?/ Todas estas cosas/ que voy a contar." (Jiménez-Díaz, 2008, p. 85). Ahora bien, de la hipérbole se pasa al sinsentido, porque en el texto se unen elementos que rompen con lo verosímil, por ejemplo las recetas que le dan a los monstruos que los engorden: "A media mañana,/ lombrices por Kilos/ con mocos de rana/ pimienta y pepino./ Después de las doce,/ para el gran almuerzo,/ lenguas de serpiente/ con mucho aderezo, sesos de gusano,/ bigotes de puerco/ y una calavera/ de un zancudo muerto" (Jiménez-Díaz, 2008, p. 86).

Este sinsentido o disparate empleado en el poemario le permite al lector niño ser partícipe del lenguaje y entrar en un mundo lúdico, de placer y disfrute, lo cual se convierte en un recurso fundamental en la literatura infantil, como lo ha afirmado Cervera (1991, p. 78): "La risa y el humor son juego, es decir, movimiento en el campo de los significados. El espíritu rígido, inflexible no se presta para el humor. Por eso el niño entra más fácilmente en el humor por la vía del juego que por cualquier otra". Además, para Origgi (2004, p. 10), el humor cumple la función de enfrentar al niño a los estereotipos culturales, que en el caso específico de Érase un monstruo se articulan con lo monstruoso, y los lleva a adoptar una posición distanciada ante ellos, una forma diferente de conocerlos y comprenderlos. 


\section{El proyecto estético de Floria Jiménez y su aporte a la literatura infantil costarricense}

Para Floria Jiménez, en su faceta como formadora de educadores, la literatura infantil es clave en el desarrollo de la sensibilidad creadora en los niños. Por ello, resulta importante el empleo de diferentes recursos que contribuyan a potenciar la creatividad y la imaginación de los niños, tales como el humor, el ritmo, la comparación y la metáfora, entre otros. Todos ellos, además de generar placer en los infantes, pueden ayudar a comprender el mundo desde perspectivas más amplias y relacionadas con los diferentes valores humanos. También se convierten en factores básicos para que el niño pueda reaccionar ante las normas que estructuran el mundo de los adultos y tener mejores espacios de crecimiento como personas.

Esta autora ha afirmado que está de acuerdo con la adaptación de los cuentos tradicionales, especialmente cuando esta se hace con el propósito de eliminar la violencia que aparece en ellos y que puede afectar la niñez: "Muchos de los cuentos tradicionales para niños han sufrido adaptaciones significativas con el pasar del tiempo, porque en ellos la violencia sobrepasa los límites saludables para un argumento infantil” (Jiménez-Díaz, 1994, p. 22). Esta posición está relacionada con el proyecto de escritura de Érase ese monstruo, libro que transforma esos seres que habitan en el imaginario infantil y le producen miedo: fantasmas, vampiros, ogros, brujas, dragones y los despoja de la temeridad que provocan acercándolos al mundo del niño. En uno de los poemas “¿Quién es el miedoso?”, se resume muy bien esta idea y se invita al niño lector a reflexionar y entender el mundo de forma diferente: “QQuién es el miedoso?/ ¿El fantasma o yo? Si te pones de cabeza,/ comprenderás la lección” (Jiménez-Díaz, 2008, p. 69).

Este poemario de Floria Jiménez cumple también con una de las funciones elementales de la literatura infantil, cual es la preocupación tanto ética como estética, orientada a colaborar con la formación del niño y encauzar sus miedos, valorando a los monstruos de una forma particular ya que pasan a ser objeto cómico más que seres que producen temor. De esta manera, por medio del humor, el niño se ríe de los monstruos, los deja de percibir como seres negativos y los acerca a su mundo.

Existe, además, en este poemario un tratamiento específico hacia estos seres monstruosos, cuya diferencia o anormalidad los ha llevado a que se les asocie con lo negativo, ya que la deformidad física aparece vinculada a la moral. Los monstruos son mirados entonces en forma comprensiva y calificados como solitarios y necesitados de afecto. Esta nueva actitud ante lo "monstruoso" se convierte en uno de los principales aportes de Floria Jiménez a la literatura infantil costarricense, ya que propicia que los niños y niñas comprendan el mundo de forma integral y logren trascender las estructuras maniqueas, que tradicionalmente han estado presentes en este tipo de literatura y en la realidad misma.

\section{Bibliografía}

Cervera, J. (1991). Teoría de la Literatura Infantil. Bilbao: Ediciones Mensajero-Universidad de Deusto.

Dautant, M. (2009). El humor en los libros para niños. Barataria. Revista Latinoamericana de Literatura Infantil y Juvenil. 11, 2-7.

Dorra, R. (1994). ¿Para qué los monstruos? Elementos. 22 (3), 13-19. 
Herra-Rodríguez, R. Á. (1987). Lo monstruoso y lo bello. San José: Editorial de la Universidad de Costa Rica.

Jiménez-Díaz, F. (1994). Música y literatura para niños. (Tomo II). San José: UNED.

Jiménez-Díaz, F. (2001). Literatura para niños. San José: Comisión Costarricense de Cooperación con la UNESCO.

Jiménez-Díaz, F. (2008). Érase este monstruo. San José: Editorial Costa Rica.

Origgi, A. (2004). Textura del disparate. Estudio crítico de la obra infantil de María Elena Walsh. Buenos Aires: Editorial Lugar.

Quesada-Pacheco, M. Á. (2007). Diccionario de costarriqueñismos. (4 ed.). Cartago: Editorial Tecnológica de Costa Rica.

Real Academia Española. (1997). Diccionario de la Lengua Española. (21 ed.). Madrid: Editorial Espasa Calpe.

Zavala, L. (1993). Humor, ironía y lectura. Las fronteras de la escritura literaria. México: Universidad Autónoma Metropolitana. 